\title{
O SISTEMA DE RESPONSABILIZAÇÃO POLÍTICA, ADMINISTRATIVA E FUNCIONAL DO REGIME CONSTITUCIONAL BRASILEIRO DE 1824: PROTÓTIPO DOS MODELOS DE RESPONSABILIZAÇÃO DAS CONSTITUIÇÕES BRASILEIRAS
}

\author{
THE POLITICAL SYSTEM OF ADMINISTRATIVE AND FUNCTIONAL \\ ACCOUNTABILITY IN BRAZILIAN CONSTITUTIONAL REGIME OF 1824: A \\ PROTOTYPE OF ACCOUNTABILITY MODELS OF BRAZILIAN CONSTITUTIONS
}

\begin{abstract}
Andrey Lucas Macedo Corrêa
Bacharelando em Direito pela Universidade Federal de Uberlândia-UFU com período de mobilidade internacional na Universidade de Coimbra-Portugal. Bolsista de iniciação científica do Conselho Nacional de Desenvolvimento Científico e Tecnológico - CNPq e bolsista de mobilidade internacional pela UFU. Pesquisador no Centro de Estudos Sociais da Universidade de Coimbra - CES/UC e pesquisador do Laboratório Americano de Estudos Constitucionais Comparados - LAECC/PPGD-UFU.

E-mail: andreylucas93@hotmail.com
\end{abstract}

\begin{abstract}
Alexandre Walmott Borges
Professor dos programas de mestrado em Direito e Gestão Organizacional da UFU -

Universidade Federal de Uberlândia. Professor visitante do mestrado em direito da UNESP - Universidade Estadual Paulista Júlio de Mesquita $\mathrm{F}^{\circ}$. Doutor em Direito pela UFSC - Universidade Federal de Santa Catarina. Doutorando em História pela UFU Universidade Federal de Uberlândia. Pesquisador líder do Laboratório Americano de

Estudos Constitucionais Comparados. Pesquisa do artigo realizada com recursos da FAPEMIG - Fundação de Apoio à pesquisa no Estado de MG e de Seminário patrocinado pela CAPES. E-mail: walmott@gmail.com
\end{abstract}

\section{Fabiana Angélica Pinheiro Camara}

Doutoranda em História social pela UFU - Universidade Federal de Uberlândia. Graduada em Administração pela Universidade de Viena. Mestra em Negócios Internacionais pela Universidade de Reading, Inglaterra. Pesquisador do Laboratório Americano de Estudos

Constitucionais Comparados. E-mail: camara.fabiana@gmail.com

Karina Almeida Guimarães Pinhão

Bacharel em Direito pela Pontifícia Universidade Católica do Rio de Janeiro - PUCRio/Brasil. Especialista em Direito Constitucional-Civil pela Universidade do Estado do Rio de Janeiro - UERJ/Brasil. Mestranda em Ciências Jurídico-políticas com menção em Direito Constitucional pela Universidade de Coimbra - Portugal. Pesquisadora do Laboratório Americano de Estudos Constitucionais Comparados - LAECC/PPGD-UFU.

E-mail: pinhao.karina@gmail.com

Recebido em: 13/06/2016

Aprovado em: 27/07/2016

Doi: $10.5585 /$ rdb.v16i7.410 
RESUMO: O artigo analisa as formas de responsabilização política, funcional e administrativa dos agentes públicos no regime constitucional brasileiro do Império (1824 até 1889). A abordagem do tema faz-se por descrição das diversas formas de responsabilização política e funcional do Império do Brasil. Os resultados provisórios mostram que o sistema imperial de responsabilização serviu de modelo aos sistemas de responsabilização do período republicano, inclusive parcialmente ao atual sistema de responsabilização vigente na constituição de 1988. As fontes de pesquisa foram a bibliografia de teoria política, teoria constitucional, e com periódicos como fontes auxiliares; na parte de problematização das formas de responsabilização no regime de 1824, a fonte principal são os documentos legislados e secundariamente os periódicos.

Palavras Chave: Responsabilidade Política. Brasil Império. Constitucionalismo. História Constitucional.

ABSTRACT: The purpose of this article is to analyse the forms of political, administrative and functional liability of Estate agents in the Brazilian constitutional system of the Empire period (from 1824 to 1889). The subject approach intends to present an overview of the various forms of political and functional liability in the period of the Brazilian Empire. Provisional results show that the imperial liability system served as model to the liability system of the Republican period, including the current partially effective liability system in the Constitution of 1988. There is a theoretical research in the context of liability in the rule of law with literature review on the topic. Subsequently, the writing process of this text is inductive, by extracting from documentary sources comprehensive descriptions of the liability forms adopted in the concrete constitutional regime of 1824. The research sources were literature review of political and constitutional theories, with periodical as auxiliary sources; when it was questioned on the liability forms in the 1824 regime, the main sources are laws and secondarily Periodicals.

Keywords: Accountability. Brazil Empire. Constitutionalism. Constitutional history.

SUMÁRIO: Introdução; 1. Responsabilidade política e funcional no ambiente do Estado de Direito; 2. Considerações gerais sobre a responsabilidade política e funcional de agentes públicos; 3.0 sistema de responsabilização política e funcional do Império Brasileiro; 4. O sistema de Responsabilização funcional dos agentes do Judiciário no Império; 5. A irresponsabilidade do Imperador, a responsabilidade dos Conselheiros e Ministros; 6. A Lei imperial de 15 de outubro de 1827; 7. A estrutura e o processo na Lei Imperial $\mathrm{n}^{\circ} 15$ de 1827; Conclusão: A permanência das estruturas da responsabilização do regime de 1824 nas constituições posteriores; Referências.

\section{INTRODUÇÃO}

O objeto de pesquisa deste artigo são as formas de responsabilização política, funcional e administrativa dos agentes públicos no regime constitucional brasileiro do Império (1824 até 1889). O objetivo geral do artigo é a descrição das formas de responsabilização política vigentes na Constituição imperial brasileira. Os objetivos específicos são os de contextualizar as formas de responsabilização da constituição imperial no ambiente do Estado de Direito e, na sequência, descrever as várias possibilidades normativas de responsabilização política da constituição imperial. A abordagem do tema faz-se por contextualização das diversas formas de responsabilização política, funcional e administrativa como formas próprias do Estado de Direito. O texto insere estas diversas formas de responsabilização dentro do estrato temporal e histórico do regime constitucional de 1824, com a narração destas formas de acordo com as propriedades e indicadores descritivos da materialidade das normas daquele período. Após, faz-se a descrição 
qualitativa das diversas formas de responsabilização deste sistema constitucional, ordenando-as de acordo com os agentes envolvidos e de acordo com o exercício funcional dos agentes, apresentando diversos sistemas peculiares de responsabilização aos diversos agentes públicos daquele período. Os resultados provisórios mostram que o sistema imperial de responsabilização serviu de modelo aos sistemas de responsabilização do período republicano, inclusive parcialmente ao atual sistema de responsabilização vigente na constituição de 1988. Ao menos os protótipos processuais e de ordenação das normas de direito material foram institucionalizados no regime de 1824.

Há na parte de contextualização da responsabilidade no Estado de Direito a pesquisa teórica, com revisão bibliográfica sobre o tema. Na sequência, o processo de realização do texto é indutivo, extraindo das fontes documentais descrições abrangentes sobre as formas de responsabilização adotadas no concreto regime constitucional de 1824. As fontes de pesquisa foram a bibliográfica de teoria política, teoria constitucional, especialmente na abordagem de contextualização do Estado de Direito, com periódicos como fontes auxiliares; na parte de problematização das formas de responsabilização no regime de 1824, a fonte principal são os documentos legislados e secundariamente os periódicos.

\section{A RESPONSABILIDADE POLÍTICA E FUNCIONAL NO AMBIENTE DO ESTADO DE DIREITO}

A ideia geral do Estado de Direito é a submissão do Estado às diretrizes estipuladas pelas normas jurídicas. Esta ideia geral é decomposta em algumas outras características essenciais para a descrição de um Estado de Direito. São consideradas características do Estado de Direito a existência de uma constituição vinculante dos órgãos do Estado; a existência de uma constituição com normas protetoras de direitos fundamentais; a partição funcional dos órgãos do Estado $^{1}$; a possibilidade de alguma forma de controle de constitucionalidade dos atos e normas; a autonomia funcional dos órgãos do Estado; e a responsabilização do Estado e dos agentes do Estado (Roig, 1999; MIRANDA, 2002; bingham, 2011).

Este último aspecto, a responsabilização do Estado, pode se realizar em diversas campos ou de diversas formas. A existência de formas de responsabilização civil do Estado, e.g., permite caracterizar este Estado como um Estado de Direito. A responsabilização pode ser tanto da pessoa jurídica Estado como do agente estatal investido da função. Além das formas de responsabilização civil, o Estado de Direito também apresenta formas de responsabilização penal dos seus agentes. Tanto no caso da responsabilização penal, como da responsabilização civil, as formas de imputação são correspondentes às formas de responsabilização aplicadas aos particulares, com variantes apenas naquilo que toca à específica forma de ação do Estado e as possíveis consequências danosas no campo patrimonial (responsabilidade civil), ou, no campo do direito penal, na redação de tipos penais próprios, aplicados à ação dos agentes públicos (MIRANDA, 2002; LOMBA, 2008).

É no campo da responsabilidade administrativa, funcional e política que o Estado de Direito apresenta regimes ou sistemas normativos diferenciados em relação aos campos originais da responsabilidade civil e penal. O Estado de Direito apresenta sistemas de normas que procuram sancionar ações políticas ou administrativas dos agentes estatais, com a previsão de tipos ou de hipóteses normativas que tomam as ações administrativas ou políticas como pressuposto de incidência de normas (canotilho, [s.d.]).

\footnotetext{
${ }^{1}$ Como disciplina o art. $5^{\circ}$ da constituição da Suíça: ' All activities of the state are based on and limited by law. State activities must be conducted in the public interest and be proportionate to the ends sought. State institutions and private persons shall act in good faith (THE FEDERAL COUNCIL, 2016).
}

Revista de Direito Brasileira | São Paulo, SP | v. 16 | n. 7 | p. 43 - 56 | Jan./Abr. 2017 
Como há a diversidade de funções estatais, desde funções administrativas à funções de governo, desde funções políticas à funções judiciais, há uma pluralidade de subsistemas normativos de responsabilização de agentes públicos no Estado de Direito. Há como exemplos subsistemas normativos para a sanção aos agentes administrativos, naquilo que toca à violação de deveres funcionais como assiduidade, eficiência, bom trato à coisa pública, respeito ao patrimônio, entre tantos. Outra forma de descrição desses subsistemas são as normas específicas de regramento da ação dos magistrados e agentes das funções jurisdicionais. Finalmente, para ilustrar esses exemplos, as formas de responsabilização típicas dos agentes políticos, como as desconfianças e censuras nos sistemas parlamentaristas de governo, aos crimes de responsabilidade nos sistemas presidenciais (Aguiar Jr., 1997).

O objeto de pesquisa deste artigo é a descrição dos sistemas normativos de responsabilização funcional, administrativa e política dos agentes públicos, no primeiro regime constitucional brasileiro, o imperial iniciado em 1822-1824. A opção do artigo por considerar o sistema constitucional de 1824 como sistema de um Estado de Direito leva em consideração o estrato temporal deste sistema (FERRAJOLI, 2009; koselleck, 2014).

Assim, algumas características e concepções daquele sistema são distintas às características e concepções do Estado de direito dos séculos XX e XXI. Tomando-se as duas dimensões materiais das constituições, as normas de direitos fundamentais e as normas de organização do Estado, o sistema de 1824 era: restrito nos conteúdos de direitos fundamentais, limitados aos direitos individuais e de nacionalidade; restrito na inclusão de pessoas no universo de sujeitos dos direitos individuais, com a persistência de coisificação dos escravos e subalternidade das mulheres; restrito nos direitos políticos com a adoção de formas de aferição patrimonial para a participação como eleitor ou como ocupante de cargos públicos; 'principesco' na forma de organização das receitas e finanças públicas e, por consequência, 'principesco' na gestão e execução das funções estatais, retroalimentando pequena elite governante; monárquico com 'sombra' de irresponsabilidade do Imperador; constrito e conciso na amplitude e ação dos órgãos do Estado.

As diferenças do Estado do regime constitucional de 1824 ao atual não podem dispensar a consideração de que o atual Estado de direito também não logra atingir algumas características: também não universaliza os direitos fundamentais (como os direito sociais); também há zonas de relatividade na igualdade no atual Estado; também há apropriações 'principescas ou burocráticas' das receitas e do exercício funcional dos órgãos do Estado. Portanto, a abordagem das características do Estado de direito - submissão às normas, existência de constituição, partição de órgãos, direitos fundamentais - é entendida aqui em sentido avaliativo e descritivo e não valorativo $^{2}$. Quando se usa a expressão avaliativo quer-se dizer que são analisadas no artigo se são detectadas a presença das estruturas do Estado de direito, e não a realização de uma valoração se são, ou não estas estruturas, material e qualitativamente determinantes do Estado de direito.

A dimensão avaliativa é a descrição com preocupação formal do Estado de direito, das estruturas que o caracterizam e que no específico objeto deste artigo são as formas de responsabilização dos agentes públicos no Estado de 1824. Assim, não há a exploração de elementos substanciais do Estado de Direito para distinguir, por exemplo, o Estado liberal do século XIX do Estado Democrático de Direito do século XX. O artigo descreve como a estrutura de responsabilização adotada em 1824 - e anos seguintes - serviu de modelo à tradição constitucional brasileira, nos vários textos posteriores.

\footnotetext{
${ }^{2}$ Ver as considerações de Ferrajolli sobre os direitos fundamentais e a sua efetivação na história constitucional (FERRAJOLI, 2009). 


\section{CONSIDERAÇÕES GERAIS SOBRE A RESPONSABILIDADE POLÍTICA E FUNCIONAL DE AGENTES PÚBLICOS}

A responsabilidade política é forma de vinculação do governante às regras do Estado de Direito, portanto com manifestação a partir da afirmação dos Estados com constituições, após o século XVII e com proliferação no século XIX. A responsabilidade política é a responsabilidade entre governantes e governados, decorrência do vínculo político entre esses atores, com repercussões sancionatórias ou consequências jurídicas no cargo ou função do agente, em função do descumprimento de certas atribuições do cargo, ou por realizar condutas típicas ofensivas à sinecura do cargo, ou condutas ofensivas à existência ou às estruturas do Estado. As formas e os sistemas de governo imprimem modelos próprios à responsabilização, variando entre a república e a monarquia, e também entre o sistema unipessoal e o sistema bipartido de governo (LOMBA, 2008; CHEIBUBI \& PRZEWORSKI, 1997; CONSTANT, 1815).

Em algumas formas de responsabilização política, além das consequências jurídicas sobre o cargo há a imposição de sanções pecuniárias, restritivas de direitos, restritivas da liberdade, ou mesmo a pena capital. A responsabilidade política é uma forma de limite constitucional do exercício funcional do agente político. A responsabilidade política tem processualística própria e normatizada, variável entre as formas ou sistemas de governo adotados por cada Estado (diferindo no presidencialismo e no parlamentarismo). A responsabilidade ocorre no ambiente próprio do Estado de Direito (LOMBA, 2008).

O sistema de responsabilização política é destinado aos agentes que pela natureza do cargo exercem funções típicas de governo, ou de direção política do Estado. O que se nota é que as formas de responsabilização política direcionadas aos agentes do Executivo não englobavam os agentes do Legislativo, ou mesmo os agentes do judiciário. As formas aplicadas aos agentes do judiciário e do legislativo são processual e substancialmente distintas àquelas do executivo.

Ao lado das formas de responsabilização política há formas de responsabilização próprias de outras funções ou de outros agentes públicos. Os exemplos destas outras formas são as normas próprias dos agentes do judiciário que potencialmente estão subsumidos aos ditames de responsabilização relacionados à prestação jurisdicional. Embora em muitos casos o tratamento dos possíveis delitos funcionais dos magistrados possam estar redigidos no mesmo texto legal dos delitos dos agentes políticos, os tipos e as hipóteses destes delitos são distintas àquelas dos agentes políticos. Um dos elementos que destaca a diferença entre os agentes do judiciário e os agentes políticos é o distanciamento da responsabilização dos magistrados de vínculos representativos com os eleitores. Como os magistrados não se submetem à rotina de eleições e sufrágio, os delitos a que estão potencialmente subsumidos são muito mais descritivos de violações das funções na prestação jurisdicional do que possíveis frustrações aos compromissos políticos, ou mesmo de possíveis atos atentatórios à soberania ou à administração pública.

Por outro lado, a responsabilização política dos parlamentares orienta-se por razões de censura e afastamento do cargo primeiramente ligadas ao juízo criminal porventura existente contra eles. O juízo criminal aqui mencionado não tem nada de original aos delitos comuns, previstos na legislação penal ordinária. O que o sistema dos parlamentares faz é determinar regras processuais específicas de processamento penal - foro privilegiado, vedação de prisões processuais - do que a existência de um sistema de previsão de normas com condutas típicas de violação de deveres funcionais, ou de específica responsabilização política.

As normas de responsabilização dos parlamentares foram se formando na história constitucional brasileira por disposições regimentais com previsões normativas que tinham por conteúdo normativo disposições de boas condutas e padrões éticos, ou como consequência de violações de impedimentos de ocupações de cargos, de patrocínio de interesses conflitantes com 
o cargo de parlamentar. Para exemplificar, as disposições sobre decoro parlamentar só ganharam previsão constitucional no ordenamento de 1946. A constituição imperial não trazia qualquer específica previsão de responsabilização dos parlamentares. Não havia previsão na constituição de 1824 de que o popular representasse ou peticionasse imputando ilícitos aos parlamentares (Cherchi, 2009; CÂMARA DOS DEPUTADOS BRASIL, 1881).

\section{O SISTEMA DE RESPONSABILIZAÇÃO POLÍTICA E FUNCIONAL DO IMPÉRIO BRASILEIRO}

O modelo de responsabilização política e funcional nacional iniciou-se com as normas do Império, na Constituição de 1824. O sistema quadripartido de órgãos estatais, dividido entre o moderador, o executivo, o legislativo e o judiciário, impunha para alguns dos agentes a responsabilização política, e para outros agentes públicos específicas modalidades de responsabilização funcional.

Uma possível primeira classificação do sistema constitucional de 1824 divide a responsabilidade política em duas modalidades de responsabilização. Uma das formas de responsabilização, foi decorrência da adoção do sistema parlamentar de governo em 1847 e que importou na atribuição de responsabilidade ao Chefe do Conselho de Ministros, e ao Conselho:

Crea hum Presidente do Conselho dos Ministros.

Tomando em consideração a conveniencia de dar ao Ministerio huma organisação mais adaptada ás condições do Systema Representativo: Hei por bem crear hum Presidente do Conselho dos Ministros; cumprindo ao dito Conselho organisar o seu Regulamento, que será submettido á Minha Imperial Approvação. Francisco de Paula Sousa e Mello, do Meu Conselho d'Estado, Ministro e Secretario d'Estado dos Negocios do Imperio, o tenha assim entendido, e faça executar. Palacio do Rio de Janeiro em vinte de Julho de mil oitocentos quarenta e sete, vigesimo sexto da Independencia e do Imperio.

Com a Rubrica de Sua Magestade o Imperador. (IMPÉRIO DO BRAZIL DECRETO N 523,1847 )

A primeira forma de responsabilização descrita no parágrafo anterior, a do parlamentarismo de 1847-1889, era construída com o sistema de responsabilização política no qual a sanção de perda do cargo não era consequência da imputação de delito. Era juízo político realizado na lógica de confiança-desconfiança, conveniência e oportunidade.

De maneira diferente àquela típica dos sistemas parlamentaristas, o sistema imperial brasileiro não repousou o juízo político de confiança-desconfiança, censura do Chefe dos Ministros, no Parlamento. Quem fazia o juízo político era o Imperador. Por isto, prodigalizou-se a expressão de que o sistema parlamentar imperial brasileiro era um 'parlamentarismo às avessas' (Horbach, 2007).

A outra forma de responsabilização política importava na imputação de condutas ilícitas aos ocupantes de cargos públicos. Já com relação a esta segunda forma de responsabilidade, com a imputação de delito e as consequências daí advindas, a Constituição Imperial fez previsão de condutas tidas como ilícitos político-constitucionais para alguns agentes públicos. O sistema de normas com previsão de ilícitos era endereçado aos agentes do Executivo e do judiciário.

A segunda classificação possível é a de que o texto de 1824 impunha a responsabilização política dos agentes públicos do Executivo que eram os Conselheiros de Estado e os Ministros do Gabinete, e de maneira diversa a responsabilização funcional dos membros do judiciário. 


\section{O SISTEMA DE RESPONSABILIZAÇÃO FUNCIONAL DOS AGENTES DO JUDICIÁRIO NO IMPÉRIO}

Os agentes do judiciário no Império sujeitavam-se ao sistema de responsabilização próprio da magistratura, sem o conteúdo de responsabilização política idêntico ao dos agentes políticos:

Art. 156. Todos os Juizes de Direito, e os Officiaes de Justiça são responsaveis pelos abusos de poder, e prevaricações, que commetterem no exercicio de seus Empregos; esta responsabilidade se fará effectiva por Lei regulamentar.

Art. 157. Por suborno, peita, peculato, e concussão haverá contra elles acção popular, que poderá ser intentada dentro de anno, e dia pelo proprio queixoso, ou por qualquer do Povo, guardada a ordem do Processo estabelecida na Lei (BRASIL Constituição de 1824, 1824).

A Lei de 14 de junho de 1831 definia competir ao/s Regente/s e aos Presidentes provinciais 'suspender os Magistrados [...] , em Conselhos, ouvindo o Magistrado, e precedendo na forma do art. 154 da Constituição'. O artigo 154 da Constituição imperial mencionado no texto da lei determinava que o Imperador podia suspender os magistrados acusados de ilícitos funcionais. $\mathrm{O}$ que a lei fez foi estender aos presidentes provinciais a competência antes atribuída à Regência e ao Monarca.

Na sequência, o artigo 11 da Lei $n^{\circ} 16$, de 1834 - Ato adicional -, tratou de definir o foro para o julgamento dos delitos de responsabilidade dos magistrados:

Art. 11. Tambem compete ás Assembléas Legislativas Provinciaes:

$\S 7^{\circ}$ Decretar a suspensão, e ainda mesmo a demissão do Magistrado, contra quem houver queixa de responsabilidade, sendo elle ouvido, e dando-se-lhe lugar á defeza. (IMPÉRIO DO BRAZIL LEI N 16,1834 )

Em 1840, a Lei da interpretação deu nova redação ao dispositivo constitucional da responsabilidade dos magistrados:

Art. $4^{\circ} \mathrm{Na}$ palavra - Magistrado - de que usa o art. $11 \S 7^{\circ}$ do Acto Addicional, não se comprehendem os Membros das Relações, e Tribunaes Superiores.

Art. $5^{\circ} \mathrm{Na}$ decretação da suspensão, ou demissão dos Magistrados, procedem as Assembléas Provinciaes como Tribunal de Justiça. Sómente podem portanto impôr taes penas em virtude de queixa, por crime de responsabilidade a que ellas estão impostas por Leis criminaes anteriores, observando a fórma de processo para taes casos anteriormente estabelecida.

Art. $6^{\circ} \mathrm{O}$ Decreto de suspensão, ou demissão, deverá contêr: $1^{\circ}$, o relatorio do facto; $2^{\circ}$, a citação da Lei, em que o Magistrado está imenso; $3^{\circ}$, uma succinta exposição dos fundamentos capitaes da decisão tomada. (IMPÉRIO DO BRAZIL LEI N 105,1840 )

\section{A IRRESPONSABILIDADE DO IMPERADOR, A RESPONSABILIDADE DOS CONSELHEIROS E MINISTROS}

No modelo de responsabilidade política do Império do Brasil o Imperador era irresponsável politicamente:'Art. 99. A Pessoa do Imperador é inviolavel, e Sagrada: Elle não está sujeito a responsabilidade alguma'. (BRASIL Constituição de 1824, 1824)

$\mathrm{Na}$ Constituição imperial, o Executivo dividia-se entre a figura irresponsável do Imperador, de acordo com o art. 99, e o Ministério, e era este último sujeito à responsabilização. 
O Ministério deveria prestar a guarda dos altos bens do Estado e não deveria adotar condutas consideradas reprováveis a esses agentes do Estado, determinados pela Constituição Imperial:

Art. 133. Os Ministros de Estado serão responsaveis

I. Por traição.

II. Por peita, suborno, ou concussão.

III. Por abuso do Poder.

IV. Pela falta de observancia da Lei.

V. Pelo que obrarem contra a Liberdade, segurança, ou propriedade dos Cidadãos.

VI. Por qualquer dissipação dos bens publicos.

[...]

Art. 135. Não salva aos Ministros da responsabilidade a ordem do Imperador vocal, ou por escripto. (BRASIL Constituição do Império do Brazil, 1824)

Além do Ministério, havia o órgão de aconselhamento do Imperador que era o Conselho de Estado. O Conselho de Estado teve várias composições na Constituição com alterações e, inclusive, a supressão em determinado período (IMPÉRIO DO BRAZIL LEI DE 12 DE OUTUBRO DE 1832, 1832; IMPÉRIO DO BRAZIL LEI N 16,1834 ; IMPÉRIO DO BRAZIL LEI N 105 , 1840; IMPÉRIO DO BRAZIL LEI N 234,1841$)$.

Da mesma forma que o Ministério, a Constituição preceituava no art. 143 que 'São responsaveis os Conselheiros de Estado pelos conselhos, que derem, oppostos ás Leis, e ao interesse do Estado, manifestamente dolosos' (BRASIL Constituição do Império do Brazil, 1824).

\section{A LEI IMPERIAL DE 15 DE OUTUBRO DE 1827}

Os delitos de responsabilidade do Ministério estavam disciplinados em regras específicas por exigência do Artigo 134 da Constituição Imperial que determinava que 'Uma Lei particular especificará a natureza destes delictos, e a maneira de proceder contra elles' (BRASIL Constituição do Império do Brazil, 1824).

A Lei de 15 de outubro de 1827 definiu os delitos de responsabilidade dos Ministros de Estado (IMPÉRIO DO BRAZIL LEI de 15 outubro de 1827, 1827). Na mesma lei foram disciplinadas as regras de responsabilização dos Conselheiros de Estado. No caso dos Conselheiros de Estado, consideradas as modificações (1832), e até mesmo a extinção em 1834, a última lei sobre o assunto foi a de 1841 (que recriou o Conselho) e trazia a seguinte redação:

Art. $4^{\circ}$ Os Conselheiros de Estado serão responsaveis pelos Conselhos, que derem ao Imperador, oppostos á Constituição, e aos interesses do Estado, nos negocios relativos ao exercicio do Poder Moderador; devendo ser julgados, em taes casos, pelo Senado, na fórma da Lei da responsabilidade dos Ministros de Estado. (IMPÉRIO DO BRAZIL LEI N 234,1841 )

\section{A ESTRUTURA E O PROCESSO NA LEI IMPERIAL N 15 DE 1827}

A estrutura da lei de responsabilização dos Ministros e dos Conselheiros é a seguinte:

a) Do art. $1^{\circ}$ ao art. $6^{\circ}$ define os tipos de responsabilização dos Ministros previstos na Constituição: a traição - art. $1^{\circ}$-; a peita, o suborno, a concussão - art. $2^{\circ}$-; o abuso de poder - art. $3^{\circ}$-; falta de observância da lei - art. $4^{\circ}$-; obrar contra a segurança, a liberdade ou a propriedade dos cidadãos - art. $5^{\circ}-$; dissipação de bens públicos - art. $6^{\circ}$ -

Como se pode ver, a estrutura das condutas consideradas reprováveis, e dos bens do Estado que mereciam especial proteção foram definidos na Lei de 1827 e acabaram se tornando o modelo geral seguido pelas normas sobre o assunto na República. 
b) As sanções envolviam desde a pena capital, passando por desonras públicas, inabilitação ao emprego, vedação de ocupação de cargos públicos, prisão, suspensão por tempos variados do exercício de qualquer emprego, e a reparação do dano provocado, nos casos nos quais havia dano material.

Nestes aspectos a Lei imperial diferenciava-se das normas adotadas pelas leis e constituições republicanas que foram editadas posteriormente. Na normatividade imperial havia a incorporação ao sistema punitivo de penas típicas do direito penal. A responsabilização ministerial era portanto penal, administrativa e política, simultaneamente. Assim, o sistema imperial brasileiro adotava uma fórmula que havia sido superada na Inglaterra, exemplo de sistema monárquico parlamentar.

$\mathrm{Na}$ Inglaterra, embora o 'impeachment' tenha surgido como forma de punição criminal de nobres, desde o século XVII havia migrado para formas de exclusiva responsabilização política, sem consequências punitivas de sanções físicas ou privativas de liberdade ${ }^{3}$. $\mathrm{O}$ sistema imperial nacional discrepou da Monarquia britânica por adotar a forma punitiva combinada, penal, política e administrativa (UK PARLIAMENT, 2016).

c) $\mathrm{O}$ art. $7^{\circ}$ da Lei tratava especificamente dos dois delitos tipificados aos Conselheiros de Estado: 'Os Conselheiros de Estado são responsaveis pelos conselhos que derem: $1^{\circ}$ Sendo opposto ás leis. $2^{\circ}$ Sendo contra os interesses do Estado, se forem manisfestamente dolosos'. Em complemento, dizia que ' incorrem nas mesmas penas, em que os Ministros e Secretarios de Estado incorrem por factos analogos a este' (IMPÉRIO DO BRAZIL LEI de 15 outubro de 1827, 1827).

d) A denúncia podia ser apresentada por qualquer cidadão. Na própria lei menciona-se que tal prerrogativa era decorrência do direito de petição inserido na constituição imperial, no art. 179, XXX. Além dos cidadãos, os membros de qualquer câmara também podiam patrocinar a petição de denúncia de delito de responsabilidade por Ministros.

Por certo o universo de cidadãos devia ser entendido dentro das limitações do regime de 1824. Não havia o universo igualitário e limitações por sexo e renda discriminavam aqueles que podiam ser compreendidos por cidadãos.

e) A legislação apresentava prazos prescricionais para o exercício do direito de petição. Para os membros das câmaras, o prazo de duas legislaturas, a contar da data do cometimento do ilícito. Ao cidadão, o prazo de 3 anos a contar da prática do delito.

f) O processamento inicial da denúncia era feito na Câmara. O processo tinha, como hoje, natureza bifásica, dividindo-se as responsabilidades entre Câmara e Senado.

g) A denúncia era recebida e encaminhada à comissão especial. A comissão poderia solicitar as provas que considerasse necessárias para o encaminhamento e escrutínio da denúncia. Após as averiguações realizadas, a comissão podia entender haver indícios da prática de ilícito. Depois da apreciação preliminar, novas reuniões da comissão (ou de outra nomeada para este fim) produzia-se parecer sobre a denúncia. O parecer era submetido à câmara. Seguindo a regra do art. 25 da Constituição, a aprovação da denúncia era por maioria absoluta.

h) Aceita a denúncia o denunciado já sofria restrições de natureza acautelatória:

$1^{\circ}$ Ficar o accusado suspenso do exercicio de todas as funcções publicas, até final sentença, e inhabilitado nesse tempo para ser proposto a outro emprego, ou nelle provido.

$2^{\circ}$ Ficar sujeito á accusação criminal.

$3^{\circ}$ Ser preso nos casos, em que pela Lei tem lugar a prisão.

$4^{\circ}$ Suspender-se-lhe metade do ordenado, ou soldo, que tiver; ou perdel-o effectivamente, se não fôr afinal absolvido. (IMPÉRIO DO BRAZIL LEI de 15 outubro de 1827, 1827)

\footnotetext{
${ }^{3} \mathrm{O}$ impeachment não é utilizado na Inglaterra desde 1806 (Gay \& Davies, 2011).

Revista de Direito Brasileira | São Paulo, SP | v. 16 | n. 7 | p. 43 - 56 | Jan./Abr. 2017
} 
A Câmara constituía comissão para apresentar a denúncia ao Senado. Esta comissão apresentava parecer de acusação à casa do Senado.

i) De acordo com a redação da lei, o Senado convertia-se em Tribunal de Justiça e ' Todos o senador são Juizes competentes para conhecerem dos crimes de responsabilidade' (IMPÉRIO DO BRAZIL LEI de 15 outubro de 1827, 1827).

j) A lista de impedimentos ou suspeições era a seguinte:

$1^{\circ}$ Os que tiverem parentesco em linha reta de ascendentes, ou descendentes, sogro, e genro; em linha collateral irmãos, cunhados, emquanto durar o cunhadio, e os primos co-irmãos.

$2^{\circ}$ Os que tiverem deposto como testemunha na fomação da culpa, ou do processo.

$3^{\circ}$ Os que tiverem demanda por si ou suas mulheres sobre maior parte de seus bens, e o litigio tiver sido proposto antes da acusação.

$4^{\circ}$ Os que tiverem herdeiros presumptivos. (IMPÉRIO DO BRAZIL LEI de 15 outubro de 1827,1827$)$

Além dos casos de impedimento ou suspeição, podia ocorrer a recusação não fundamentada de 6 Senadores.

k) Após a comunicação do recebimento do libelo, determinava-se o prazo para a sessão de julgamento. Pela lei, o julgamento era pautado pela contradita entre a comissão de acusação e a defesa do acusado. Senadores poderiam encaminhar perguntas durante a sessão de julgamento.

1) A lei previa a realização de sessão secreta para a verificação da suficiência de tudo o que foi produzido em julgamento. Somente com a confirmação da suficiência podia-se encaminhar a matéria ao julgamento pelo Tribunal do Senado.

m) A sessão definia a procedência ou improcedência da acusação. Além disto, o Presidente encaminhava os quesitos de aplicação da pena: ao grau máximo, médio ou mínimo de apenação.

n) Da decisão cabia como único recurso os embargos. O prazo máximo para a apreciação era de dez dias após a sessão de julgamento.

O sistema de responsabilização ministerial e conselheirático vigeu durante todo o Império. Com a proclamação republicana tornou-se sistema de normas com cessação de existência, pelas mudanças de forma de governo e sistema de governo, com o advento da ordem constitucional de 1889.

\section{CONCLUSÃO: A PERMANÊNCIA DAS ESTRUTURAS DA RESPONSABILIZAÇÃO DO REGIME DE 1824 NAS CONSTITUIÇÕES POSTERIORES}

A constituição imperial de 1824 inseriu várias formas de responsabilização política dos agentes políticos. A estrutura da constituição imperial mostra que o sistema constitucional brasileiro, nesta que é a primeira manifestação constitucional nacional, já havia definido um sistema de fiscalização e sinalagma entre governantes e governados. O sistema constitucional de 1824 definia formas de responsabilização em dois grandes blocos: uma, aquelas típicas de sistemas parlamentares de governo, com a sanção de perda de cargo; a outra, ao lado desta típica sanção parlamentar, havia a previsão de típicos ilícitos funcionais. Portanto, o sistema imperial comportava duplicidade de juízos: um essencialmente político, de manutenção ou queda motivada por fatores políticos (confiança/desconfiança), com a participação do Imperador e do parlamento; outro, já com previsões tipificadas em normas nas situações de ilícitos cometidos no desempenho funcional. Este último é que serviu de base aos sistemas republicanos de crimes de responsabilidade. O sistema republicano extirpou a forma essencialmente política de 
responsabilização do parlamentarismo imperial adotando somente a forma de responsabilização pela prática de ilícitos políticos.

A despeito da exceção da irresponsabilidade do Imperador, a constituição imperial definiu formas processuais e materiais de responsabilização dos agentes políticos nas situações de desempenho insuficientes, ofensas à coisa pública ou traição, ofensas aos direitos dos súditos, lesões ao Estado de Direito, e condutas lesivas ao erário. Todo este microssistema de responsabilização encaixa-se na ideia central do Estado de Direito, de responsabilização dos governantes pelo exercício funcional em nome dos governados, mostrando a precocidade e ineditismo do sistema brasileiro na adoção deste modelo de representação política da soberania popular. A exceção de irresponsabilidade do Imperador encaixava-se, porém, dentro da lógica e desenho institucional das constituições imperiais novecentistas(e ainda existente em sistemas de governo monárquicos), não constituindo casuísmo ou anomalia do texto de 1824 . As constituições republicanas posteriores incluíram o chefe do executivo, o presidente da república, no rol dos sujeitos passíveis de responsabilização.

No sistema constitucional de 1824 já ficaram definidas as regras básicas do processo e da materialidade dos julgamentos por responsabilidade política. O período imperial mostra que as estruturas de responsabilização política pela prática de ilícitos administrativos-funcionaispolíticos dos agentes tornaram-se tradição no direito constitucional brasileiro. Todas as constituições nacionais posteriores encerraram conteúdos e disposições normativas de responsabilização dos agentes públicos com as estruturas da responsabilização do regime de 1824 servindo de modelo aos ciclos constitucionais posteriores..

A responsabilização de Ministros de Estado, e do chefe do Executivo do período imperial, o Chefe do Gabinete, e dos Conselheiros de Estado, mostra que a responsabilização da direção do executivo está presente desde o regime de 1824. A diferença é que o regime republicano alterou as disposições sobre responsabilidades dos membros do executivo que são os ministros, determinando o julgamento pelo STF, e não mais pelas casas legislativas. Nas constituições republicanas os ministros perderam o destaque de responsabilidade perante $\mathrm{o}$ parlamento já que passaram a ser indicados do chefe do executivo presidencial. Com a menor estatura política dos ministros, o sistema republicano retirou a modalidade de responsabilização perante o parlamento, restando a fórmula única de julgamento por crimes de responsabilidade perante órgão do judiciário.

Se por um lado o sistema republicano esvaziou as possibilidades de julgamento dos ministros, a forma básica de processamento e julgamento dos crimes envolvendo o Presidente da República, bifásica, com a admissibilidade na Câmara e o julgamento no Senado, é tradição iniciada no julgamento do período imperial, de Ministros e Conselheiros. O sistema republicano fez a transposição do sistema de julgamento dos Ministros e conselheiros para o chefe do executivo, o presidente. Tal como hoje, e no começo do regime republicano, a acusação era analisada pela Câmara e, admitida, julgada pelo Senado.

As autoridades atípicas incluídas no rol de sujeitos passíveis de imputação de crime responsabilidade, no período republicano, como os membros do Judiciário - Ministros do STF -, já eram passíveis de punição por responsabilidade no sistema de 1824. O sistema de responsabilização de 1824 já previa que magistrados respondessem por delitos funcionais. $\mathrm{Na}$ verdade, o sistema de 1824 era tão amplo quanto o de 1891, já que incluía todos os juízes, ao contrário do que prevaleceu no sistema republicano nas constituições posteriores, de inclusão somente dos Ministros do STF e juízes federais ${ }^{4}$.

\footnotetext{
${ }^{4}$ A partir de 1891 houve a inclusão das seguintes autoridades como passíveis de praticarem crimes de responsabilidade: presidente, ministros de Estado e ministros do STF. Presidente e Ministros de Estado (estes últimos se cometessem crimes conexos aos do presidente), julgados pela sistema bifásico, Câmara-Senado. Os ministros do STF julgados pelo Senado. Os ministros de Estado, se não houvesse a conexão, no STF. A Constituição Revista de Direito Brasileira | São Paulo, SP | v. 16 | n. 7 | p. 43 - 56 | Jan./Abr. 2017
} 
Como fecho conclusivo:

a) as constituições republicanas não contemplaram a forma de julgamento essencialmente político, perante o parlamento, existente na constituição de 1824;

b) as constituições republicanas assimilaram o conteúdos da figuras de responsabilidade política da constituição imperial, naquilo que eram os ilícitos praticados pelos agentes políticos e definidos em condutas típicas de crimes políticos;

c) as formas dos crimes políticos do regime imperial foram incorporadas ao sistema republicano como crimes de responsabilidade;

d) a irresponsabilidade política do Imperador foi substituída pela responsabilidade do Presidente, e este responde com a fórmula adotada pelo Império para o julgamento de ministros e conselheiros de Estado.

\section{REFERÊNCIAS}

AGUIAR JR., R. R. Responsabilidade política e social dos magistrados nas democracias modernas. Revista da Ajuris, Porto Alegre, jul. 1997. 7-33.

BINGHAM, T. The rule of law. Londres; Nova Iorque; Canberra: Penguin, 2011.

BRASIL CONSTITUIÇÃO DE 1824. Constituição do Império do Brazil de 25 de março de 1824. Planalto legislação, Brasília, 1824. Disponivel em: <http://www.planalto.gov.br/ccivil_03/Constituicao/Constituicao24.htm>. Acesso em: 02 abr. 2016.

BRASIL CONSTITUIÇÃO DO IMPÉRIO DO BRAZIL. Constituição do Império do Brazil de 25 de março de 1824. Planalto legislação, Brasília, 1824. Disponivel em: <http://www.planalto.gov.br/ccivil_03/Constituicao/Constituicao24.htm>. Acesso em: 02 abr. 2016.

CÂMARA DOS DEPUTADOS BRASIL. Regimento interno da Câmara dos Deputados. Biblioteca digital da Câmara, 1881. Disponivel em: <file://CC:/Users/walmott/Downloads/regimento_camara_1870_1881.pdf>. Acesso em: 16 abr. 2009.

CANOTILHO, J. J. G. Libertarianismo. Estado de Direito. Libertarianismo, [s.d.]. Disponivel em: 〈http://www.libertarianismo.org/livros/jjgcoedd.pdf>. Acesso em: 01 jul. 2016.

CHEIBUBI, J. A.; PRZEWORSKI, A. Democracia, eleições e responsabilidade política. Revista brasileira de ciências sociais, São Paulo, fev. 1997.

CHERCHI, G. S. Renúncia do mandato parlamentar na Câmara dos Deputados por falta de ética ou quebra do decoro parlamentar. Biblioteca digital Câmara, 2009. Disponivel em: <file:///C:/Users/walmott/Downloads/renuncia_mandato_cherchi.pdf>. Acesso em: 09 abr. 2016. 
CONSTANT, B. Principes de politique - applicable a tous les gouvernemens représentatifs. Paris: Chez Alexy Eymery, 1815.

FERRAJOLI, L. Derechos Fundamentales. In: AL., L. F. E. Los fundamentos de los derechos fundamentales. Madri: Trotta, 2009.

GAY, O.; DAVIES, N. Impeachment. House of Commons Library. Londres, p. 1-6. 2011.

HORBACH, C. B. O parlamentarismo no Império do Brasil (II). Revista de informação legislativa, Brasília, abr.-jun 2007. 213-231.

IMPÉRIO DO BRAZIL DECRETO N 523. Decreto n ${ }^{\circ} 523$ de 20 de julho de 1847. Câmara dos Deputados Legislação, 1847. Disponivel em: <http://www2.camara.leg.br/legin/fed/decret/18241899/decreto-523-20-julho-1847-560333-publicacaooriginal-83096-pe.html>. Acesso em: 09 abr. 2016.

IMPÉRIO DO BRAZIL LEI DE 12 DE OUTUBRO DE 1832. Lei de 12 de outubro de 1832. Planalto legislação, $1832 . \quad$ Disponivel em: <http://www.planalto.gov.br/ccivil_03/LEIS/LIM/LIM-12-10-1832.htm>. Acesso em: 03 abr. 2016.

IMPÉRIO DO BRAZIL LEI DE 15 OUTUBRO DE 1827. Lei de 15 de outubro de 1827. Câmara dos Deputados - legislação informatizada, 1827. Disponivel em: <http://www2.camara.leg.br/legin/fed/lei_sn/1824-1899/lei-38389-15-outubro-1827-566674publicacaooriginal-90212-pl.html>. Acesso em: 16 abr. 2016.

IMPÉRIO DO BRAZIL LEI N ${ }^{\circ}$ 105. Lei ${ }^{\circ} 105$ de 12 de maio de 1840. Planalto legislação, 1840. Disponivel em: 〈http://www.planalto.gov.br/ccivil_03/LEIS/LIM/LIM105.htm>. Acesso em: 03 abr. 2016.

IMPÉRIO DO BRAZIL LEI N ${ }^{\circ}$. Lei n 16 de 12 de agosto de 1834. Planalto legislação, 1834. Disponivel em: <http://www.planalto.gov.br/ccivil_03/LEIS/LIM/LIM16.htm>. Acesso em: 03 abr. 2016.

IMPÉRIO DO BRAZIL LEI N 234. Lei n 234 de 23 de novembro de 1841. Planalto legislação, 1841. Disponivel em: <http://www.planalto.gov.br/ccivil_03/leis/LIM/LIM234.htm>. Acesso em: 03 abr. 2016.

KOSELLECK, R. Estratos do tempo. 1. ed. ed. Rio de Janeiro: Puc, 2014.

LOCKE, J. Dois tratados sobre o governo. São Paulo: Martins Fontes, 1998.

LOMBA, P. Teoria da responsabilidade política. Coimbra: Coimbra, 2008.

MIRANDA, J. Teoria do Estado e da Constituição. Rio de Janeiro: Forense, 2002. 
ROIG, R. D. A. Una aproximación a los modelos de los Estados de derecho. Madri: Dykinson, 1999.

THE FEDERAL COUNCIL. Federal Constitution of the Swiss Confederation. The portal of Swiss government, 2016. Disponivel em: <https://www.admin.ch/opc/en/classifiedcompilation/19995395/index.html\#a5>. Acesso em: 31 mar. 2016.

UK PARLIAMENT. Impeachment. UK Parliament Glossary, 2016. Disponivel em: <http://researchbriefings.parliament.uk/ResearchBriefing/Summary/SN02666>. Acesso em: 03 abr. 2016. 